\title{
Losses by pests on food products and their controls for hygiene environment in hotels
}

\author{
Garima Goyal*, Vishal Kumar ${ }^{1}$ and Lalit Kumar ${ }^{1}$ \\ Subharti Institute of Hotel Management \\ Swami Vivekanand Subharti University, Meerut 250005 (U.P.) \\ ${ }^{1}$ Department of Agricultural Engineering and Food Technology \\ Sardar Vallabhbhai Patel University of Agriculture and Technology, Meerut 250110 (U.P.) \\ "Email: garimajainjain@ymail.com
}

\begin{abstract}
Rodents may consume human food at all stages of production and processing, including transportation of food to its final destination. In commercial factories that produce food for human consumption, the presence of rodents may be very hazardous and costly. They not only cause the loss of food that they consume, but also the whole portion or batch of food in the vicinity that they have come in contact. This is caused by crosscontamination, through droppings, urine and hair mostly. In this respect, a large batch of product must be disposed of due to health risks. If a rodent damages food during preparation, the cost to remove the damage may outweigh the cost of the food itself, and the food would then be wasted. It is not unusual to consider spending extra money to buy high quality, nutritious food, but many people overlook the quality of their food storage containers. A food container that is considered high quality will be made of glass, stainless steel or ceramic, which all can withstand a fluctuation in temperate without warping or cracking. The container should also seal tightly and not be prone to deep scratches.
\end{abstract}

Key Words: Food Quality, Rodents, Fly Insects and Controls

Paper cited: Goyal, G., Kumar, V. and Kumar, L. (2015). Losses by the pests on food products and their controls for hygiene environment in hotels. South Asian Journal of Food Technology and Environment, 1(3\&4): 284-289.

Received: 21/09/2015 Revised: 15/11/2015 Accepted 29/11/2015

\section{Introduction}

Food borne illness continues to be an urgent issue. The food safety and inspection service educate consumers about the importance of safe food handling and how to reduce the risk associated with food borne illness. The great majority of people will experience a food or water borne disease at some point in their lives. This highlights the importance of making sure the food we eat is not contaminated with potentially harmful bacteria, parasites, viruses, toxins and chemicals. General information on stored food losses at the farm and village level in developing countries is sparse and poorly documented. While it is known that millions of people throughout developing countries share their meagre households and foods with rats, mice, and pest birds. These problems mainly have escaped documentation by scientists and agriculturists. Farm families, living in or near poverty and nutritional catastrophe, suffer a double loss - a portion of their crop both before as well as after harvest. During the ensuing two decades since these reports were issued, very little new information on stored food losses at the farm and village level was added. Several conferences and books on rodents since 1980 have only touched on the subject of stored food losses (Dubock, 1982; Meehan, 1984; and Richards and $\mathrm{Ku}, 1986)$. Table 1 shows stored losses at farm and village level.

Good quality food for health 
"A calorie is a calorie" is an oftrepeated dietary slogan, and not overeating is indeed an important health measure. Rather than focusing on calories alone, however, emerging research shows that quality is also a key in determining what we should eat and what we should avoid in order to achieve and maintain a healthy weight. Rather than choosing foods based only on caloric value, think instead about choosing high-quality, healthy foods, and minimizing low-quality foods. High-quality foods include unrefined, minimally processed foods such as vegetables and fruits, whole grains, healthy fats and healthy sources of protein - the foods recommended in the Healthy Eating Plate. Lower-quality foods include highly processed snack foods, sugar-sweetened beverages, refined (white) grains, refined sugar, fried foods, foods high in saturated and trans-fats, and high-glycemic foods such as potatoes.

Table 1: Stored food losses at farm and village level

\begin{tabular}{|l|l|l|c|}
\hline Area & Type of Storage & Commodities & $\begin{array}{l}\text { Percent damage } \\
\text { or loss }\end{array}$ \\
\hline Bangladesh & Bamboo bins & Rice, wheat & 5 \\
\hline India & Village stores & Rice, wheat & 1.7 \\
\hline India & Village, bags & Rice, wheat, millet, sorghum & $3.5-5$ \\
\hline India & Bins, Bags & $\begin{array}{l}\text { Mud and bamboo rice, wheat, } \\
\text { pulses, sorghum }\end{array}$ & $2-5$ \\
\hline Korea & Sacks & Rice, barley & 20 \\
\hline Laos & Cribs, mud and bamboo bins & Rice & 3 \\
\hline Malaysia & Cribs in roof & Rice & $2-5$ \\
\hline Nepal & Sacks & Maize & $3-5$ \\
\hline Philippines & Cribs, sacks & Rice, maize & $2-3$ \\
\hline Thailand & Sacks in roof, maize in cribs & Maize, rice & 5 \\
\hline Turkey & $\begin{array}{l}\text { Farm houses, underground } \\
\text { pits }\end{array}$ & Wheat, rice, maize & 5 \\
\hline
\end{tabular}

Source: Hopf et al., (1976).

\section{Quality counts}

One study analyzed whether certain foods were more or less likely to promote weight gain. This type of research examining specific foods and drinks allows us to understand whether "a calorie is a calorie," or if eating more higher-quality foods and fewer lower-quality foods can lead to weight loss and maintenance. Researchers in the Department of Nutrition at Harvard School of Public Health show us that quality is in fact very important in determining what we should eat to achieve and maintain a healthy weight, and that the notion of "a calorie is a calorie" does not tell the whole story. In a study of over 120,000 healthy women and men spanning 20 years, researchers determined that weight change was most strongly associated with the intake of potato chips, potatoes, sugarsweetened beverages, and both processed and unprocessed red meats. The researchers concluded that consumption of processed foods higher in starches, refined grains, fats, and sugars can increase weight gain.

Foods shown to be associated with weight loss were vegetables, whole grains, fruits, nuts, and yogurt. Researchers did not discount the importance of calories, instead suggesting that choosing high-quality foods (and decreasing consumption of lower-quality foods) is an important factor in helping individuals consumes fewer calories. After one year, weight loss was greater for women in the 
Atkins diet group compared with the other diet groups.

This study also examined secondary outcomes focused on metabolic effects (such as cholesterol, body fat percentage, glucose levels and blood pressure), and found that those for the Atkins group were comparable with or more favorable than the other diet groups. There was no significant difference in weight loss among the other three diets (Zone, LEARN, and Ornish). This study does raise questions about about long-term effects and mechanisms, but the researchers concluded that a low-carbohydrate, high-protein, high-fat diet may be considered a feasible recommendation for weight loss.

\section{Common pests and their control Housefly}

The housefly is one of the filthiest of pest and is found all over the world. It has a hairy body, three pairs of legs, each having a pad with glandular hairs. Secretions from these pads enable dirt and germs to stick to it, which is later transferred to food, equipment or any other surface it lands on. Flies spread diseases of the intestine, nose, and throat. Serious illness like tuberculosis, typhoid, cholera etc is a result of poor sanitary conditions. A single fly can carry $280,00,000$ bacteria in its alimentary hairy body and feet. The fly has a powerful sense of smell and is attracted to uncovered garbage, dirty toilets, food waste, empty food packets, cartons, used single serviced items etc. it breeds close to its source of food in damp, filthy areas. The fly is most active at temperatures between 26 and $32^{\circ} \mathrm{C}$. Flies are attracted to light and being winged insects are affected by wind currents.

\section{Control Measures}

- Environmental sanitation can be achieved by proper disposal of garbage, decaying food and animal carcasses and other wastes.

- All food waste should be held in tightly covered bins and preferably refrigerated to reduce decay and fly activity. Clean garbage containers thoroughly.
- Protective display of food using fly proof cupboards, wire gauze cover etc should be practiced.

- Self closing doors and windows prevent their entry.

- Various insecticidal sprays, aerosols and pellets are effective in controlling fly populations in kitchens and food service areas.

- Poisonous baits and fly strips are a combination of an insect attracting food like sugar and an insecticide. Since they are poisonous they should be used and stored with care. They are recommended for outdoor use.

- Insect light traps (ILT) - all species of flies are naturally attracted to UV light. This property is made use of in attracting and trapping flies. These are designed to attract houseflies by emitting UV light and are popularly used at food handling facilities like restaurants, kitchens, factories and warehouses. The UV light is strongly attractive to insects. It is set in an electrified grid which kill insect flying through it .dead insects fall in a pan which should be regularly emptied.

\section{Fruit Fly}

These are seasonal, colored and smaller than the housefly. They are most attracted to overripe and decaying fruit. These pests are not attracted to sewage and other wastes; hence transmit less number of micro organisms. Their larvae eat their way through different fruits and spoil them.

Control Measures

- Check fruit supplies for signs of infestations.

- Get rid of decaying fruit and other fermenting food stuffs.

- Use screens, wire meshes and air currents to prevent their entry.

- Electric fly traps to a certain extent are useful in exterminating them. 


\section{Blow Flies and Flesh Flies}

Blow flies are large flies seen especially during warm summer months. They are also called bottle flies and have a metallic blue or green color. They breed on animal and bird carcasses, meat scraps, animal excrement in the environment or in garbage bins and are attracted by a foul smell. They lay their eggs where they feed, and eggs hatch quickly into young larvae, called maggots. Blowfly maggots have recently been adopted by some physicians to treat gangrenous wounds as some species will only eat dead tissue. Flesh flies like blow flies also breed in carrion, dung or decaying material. Flesh flies are also large and grey or black in colour. They also eat decaying vegetables matter and excrement and may be found around compost pits. They can carry leprosy bacilli and can transmit intestinal pseudomyiasis to people who eat the flesh fly larvae.

\section{Control measures}

- Since blow flies and flesh flies breed in rotting flesh and garbage, sanitation is the most important step in controlling them.

- Eliminate all potential breeding places such as mulch, manure, garbage and animal excrement.

- Garbage should be drained and wrapped in garbage bags before being placed in bins. This will reduce odour that attract egg laying flies.

- Use adequate screens of 10 meshes on doors and windows to prevent the entry of flies.

- Screen doors should open outward and have fitted springs for tight closing.

In food preparations and service areas to keep flies away use 50 watt high pressure sodium vapour lights or non insect attractant light instead of a 100 watt mercury vapour light so that flies are not attracted. In case of heavy fly populations, it is best to call the pest control agency.

\section{Cockroaches}

The cockroach is another resilient pest known to man. It is filthy and gives off a foul odour. Cockroaches contaminate unprotected food, utensils and other surfaces. They travel from sewers to garbage dumps. En route, they collect numerous disease causing micro organisms on their bodies and in their stomachs. Uncontrolled cockroach infestations could spread diseases such as diarrhea, dysentery, typhoid fever, intestinal worms, food poisoning. Cockroaches may go undetected unless there is a heavy infestation. They prefer to venture out at night as they are sensitive to light. They are found almost everywhere in buildings, cracks, crevices, food containers, uncleared garbage. They breed in dark, damp, undisturbed places. Besides the nauseating odour they emit discarded egg capsules, body wastes and body parts are the sure signs of a cockroach menace in a catering facility. Cockroaches appearing during the day time indicate a heavy build up.

\section{Control measures}

- Persistent efforts at maintaining good sanitary conditions are the key to cockroach control. Covering dustbins at night, keeping food service areas free from dirt and food particles as well as prompt garbage disposal are essential.

- All cracks and crevices should be properly sealed.

- Good lighting and ventilation prove to be a deterrent to pest favoring dark, damp places to rest and breed.

- Protect food from contamination by proper storage. Scrutinising bags and sacks for insect eggs and body parts help check the entry of these pests into the premises.

- Permitted insecticides should be applied to cracks and crevices, undersides of tables, cupboards, equipments, behind sinks and other areas likely to harbor these pests.

- Cockroach traps should be installed over drains. 
Ants

These common but annoying pests are known to transmit diseases from excrement to food. Ants cause immense wastage of food by eating some of it, thus making the food unfit for human consumption. They are known to destroy crops and also eat into wrappers. These social pests are so called, as they exist in groups or colonies and work together. Their nests, which contain thousands of ants, are found in spaces between walls, under floors and in undisturbed litter outside buildings. Ants prefer sweets and fatty foods. While some like meats, other is even known to eat into wood and weaken building structure. They can be harmful as they bite and sting. They attract other pests like cockroaches. The appearance of ants in a food service department indicates poor hygienic conditions.

Control measures

- Good sanitary practices should be followed.

- Food should be kept covered.

- Suitable pesticides should be applied.

\section{Mice and Rats}

Both types of rodents share many characteristics. Both are hazardous. Mice are generally much smaller and are slender enough to squeeze through holes as small as $6 \mathrm{~mm}$ in diameter. Physically mice have big ears, brown coats, and grey underbellies. They also have a thin tail that is equal to the length of their head and body combined. Rats and mice both carry germs and may cause food poisoning, infection, jaundice etc. Mice, like rats, can contaminate food stuffs, worktops, utensils with their urine, droppings, fur and are responsible for the spread of many diseases, some of which can be fatal to humans. Table 2 shows amount of food consumed daily and yearly by rodents infesting stored foods.

\section{Control measures}

The most effective methods of controlling these pests are poisoning, trapping, fumigating to eliminate their food supply and shelter and rat proofing buildings. Poisons are available to destroy rats and mice.

Table 2: Amount of food consumed daily and yearly by rodents infesting stored foods

\begin{tabular}{|l|c|c|}
\hline Rodent Species & $\begin{array}{c}\text { Amount of food } \\
\text { consumed daily }(\mathbf{g})\end{array}$ & $\begin{array}{c}\text { Amount of eaten yearly } \\
\text { (kg) }\end{array}$ \\
\hline Norway rat, Rattus norvegicus & $15-25$ & $6-9$ \\
\hline Roof rat, . rattus & $8-12$ & $3-4$ \\
\hline Polynesian rat, R. exulans & $5-8$ & $2-3$ \\
\hline Bandicoot rat, Arvicanthis niloticus & $15-25$ & $6-9$ \\
\hline Unstriped grass rat, Arvicanthis niloticus & $5-8$ & $2-3$ \\
\hline Multimammate rat, Mastomys natalensis & $5-8$ & $2-3$ \\
\hline Spiny mouse, Acomys cahirinus & $3-6$ & $1-2$ \\
\hline House mouse, Mus musculus & $2-3$ & $0.7-1$ \\
\hline Vesper mouse, Calomys laucha & $3-5$ & $1-2$ \\
\hline Grass mouse, Akodon azarae & $3-5$ & $1-2$ \\
\hline
\end{tabular}

Sources: Brooks and Fiedler (1999)

\section{Conclusion}

Rodents and insects infestation have been a nuisance to humankind and have destroyed and contaminated food at all stages of food production and service. The presence of pests, their body parts or droppings in food served will not only result in contamination and spread of disease but can ruin the reputation of any catering establishment. Pests commonly found are flies, cockroaches, ants, rats, mice, animals and birds. The key to any effective pest control programme is patient and persistent sanitary measure. Having understood the immense economic loss, wastage and health hazard which can occur as a consequence of a pest infestation, it is 
imperative that this aspect of pest eradication is not neglected in any catering operation. Using professional help could prove beneficial for short period of time. It is up to the food service worker to maintain the premises pest free.

\section{References}

1. Brooks, J.E. and Fiedler, L.A. (1999). Vertebrate pests post harvest operations. United State Department of America (USDA).

2. Dubock, A. C. (1984). Proceedings of a Conference on the Organization and Practice of Vertebrate Pest Control. Elvetham Hall, UK. 30 August-3 September 1982.

3. Hopf, H.S., Morley, G.E.J. and Humphries, J.R.O. (1976). Rodent damage to growing crops and to farm and village storage in tropical and subtropical region. Centre for Overseas Pest Research and Tropical Product Institute, London (UK). pp. 155

4. Meehan, A.P. (1984). Rats and Mice, Their Biology and Control. Rentokil Ltd. East. Grinstead, UK. pp. 383.

5. Richards, C.G.J. and Ku, T.Y. (1986). Control of Mammal Pests. Taylor and Francis, London, UK. 